\title{
Psychological Safety of an Inclusive Educational Environment: Criteria, Content and Assessment Methods
}

\author{
Elena Slusareva ${ }^{1}$, Alexey Dontsov $^{1}$ \\ ${ }^{I}$ State budgetary educational institution of higher education, "Stavropol State Pedagogical \\ Institute”, Stavropol, Russia
}

Keywords: Psychological Safety, Inclusive Educational Environment.

\begin{abstract}
The purpose of the study: theoretical justification and empirical study of the psychological security of an inclusive educational environment. To achieve this goal, the following research methods were used: theoretical (systematic scientific and methodological literature on the problem of ensuring the psychological security of an inclusive educational environment); empirical (experiment, survey method, expert assessment method); methods of primary mathematical statistics. Research results: the concept of psychological security of an inclusive educational environment is considered; the content of its components: subject-semantic, substantive-methodical, communicationorganizational. Criteria of psychological safety of an inclusive educational environment are highlighted and substantively substantiated: attitude to inclusive educational practice, satisfaction with the main substantive components of an inclusive educational environment, and protection from psychological violence. In accordance with the criteria of psychological safety of an inclusive educational environment, methods for studying psychological safety indicators have been selected and tested. Based on the results obtained, factors and risks arising in an inclusive educational environment and affecting its psychological safety are identified.
\end{abstract}

\section{Introduction}

The problem of personal security is one of the urgent, interdisciplinary problems and is considered from the perspective of the functioning and development of social, economic, technical, environmental and biological systems.

Development, health, the normal state of society and the individual is impossible without ensuring national security and the security of the socio-economic system of the state [11]. The school as an educational and social institution builds a local security system based on the general theory of security [1].

The safety phenomenon is presented in a number of methodological approaches: philosophical, sociological, legal, cybernetic, socio-psychological, mathematical, etc. In this paper, we will present a psychological approach to the safety phenomenon of the educational environment, which includes children with disabilities.

A number of studies show that children and adolescents with developmental disabilities are at risk for factors determining the violation of psychological safety, and especially when they are 
trained or brought up with normally developing children (i.e., in an inclusive education). This is a group of children in a high degree of dysfunction in terms of insecurity from violence, dissatisfaction with the educational and interpersonal environment [4]. The readiness of educational systems to design an effective and safe inclusive educational environment for the implementation of joint learning for children with disabilities and healthy children is one of the factors in building an effective model of inclusive education [8].

Based on the relevance of the problem, we determined the purpose of the study: a theoretical justification and an empirical study of the psychological security of an inclusive educational environment.

\section{Text Organization}

\subsection{Theoretical theses}

The concept of psychological safety of the educational environment is a system of views on ensuring the safety of participants from threats to positive development and mental health in the process of pedagogical interaction [1].

In general, the psychological security of the individual is considered in connection with the mobilization of the resources of the human psyche in difficult and extreme conditions, and the realization of the need for security is considered as preserving the psychological integrity of the individual, having a sense of satisfaction with the present and confidence in the future, a sense of security of interests and values, inclusion into the surrounding reality. Psychological safety experienced by the participants as a state of protection from psychological violence, satisfactorily concern the basic needs of student-confidential communication is a condition that triggers the positive opportunities of mental and professional development of all the subjects of the educational process: children, parents and teachers [1].

In turn, a psychologically safe inclusive educational environment is defined as an open educational environment with a predominance of a humanistic tendency and a dialogical orientation, free from psychological violence, referentially significant for each subject of educational activity, including all necessary means for fulfilling the needs, capabilities and abilities of each individual independently from his physical and (or) mental development, sociocultural preferences, religious and ethnic origin reports [5].

Psychological safety involves a targeted impact on the entire socially significant environment of a child with disabilities, including parents and teachers, and is aimed at developing the psychological skills of partnership, dialogue, safe psychological interaction and cooperation of subjects of the educational process [14].

E.B. Laktionova, following the ideas of L.S. Vygotsky, means that the environment determines the development of the child through his experience of this environment and considers the educational environment as a multi-level interaction between its subjects, which makes it possible, on the one hand, to determine the quality of mental phenomena that are mediated by this interaction, and, on the other hand, - evaluate the psychological quality of the educational environment, which will either contribute to the development of the personality of its subjects, or generate deformations and deviations in their development $[3,7]$.

The most significant, according to the author, are the characteristics of the educational environment, reflecting the quality of the processes of interaction and the nature of the relationship between the subjects of the educational process. The psychological characteristics of the educational environment are considered: attitude to the educational environment, satisfaction with the basic characteristics of the interaction and protection from psychological violence. 
Thus, psychological safety is a leading characteristic that determines the developing nature of an inclusive educational environment.

\subsection{Criteria and research methods}

As a result of a theoretical analysis of the literature on the research problem and relying on the psychological approach to the analysis of the educational environment, proposed in the study of E.B. Laktionova, we identified the following criteria for assessing the psychological safety of an inclusive educational environment: attitude towards the educational environment, satisfaction with the main characteristics of an inclusive educational environment, and security from psychological violence [3]. These criteria are expressed in the content of each component of an inclusive educational environment.

Based on the research of S.V. Tarasov [12], we will single out the following components in the structure of an inclusive educational environment and consider their content that provides the basic need for subjects of educational relations - the need for psychological safety:

1. The subject-semantic component involves a certain subject and spatial organization of the environment, which allows to minimize the feeling of uncertainty and fear in a child with special needs in psycho-physical development (architectural, information accessibility, special teaching aids). This is the accessibility of classes and other premises of the school (creating a barrier-free environment); technical means of providing comfortable access (assisting means and technologies); correctional-developing subject environment for training and socialization; premises (zones) for rest, restoration of working capacity, improvement, etc.

2. The content-methodical component is the content and methods of organizing training that maximize the disclosure of the capabilities of a child with disabilities. The use of any equipment, software product should be combined with a personality-oriented approach through the development of adapted educational programs, individual educational routes, the use of special educational technologies, the active use of alternative communication tools: selective and topographic (fingerprinting, sign language, etc.).

The key principle in building an inclusive educational environment is the principle of conformity: the special educational needs of the child with his abilities and the creation of special educational conditions that correspond to the needs and capabilities of both the child with disabilities and other categories of children $[10,13]$. It is very important that the influence of the personality of the teacher and pedagogical influences is nature-friendly features and capabilities of children with disabilities and leads to the developing nature of the interaction in an inclusive educational environment.

3. The communication and organizational component, the main essence of which is immersion in the system of social relations: the positive impact of interpersonal interactions of various participants in the educational process on the features and specific manifestations of the learning environment, on the development of students with different psychophysical status. The organization of a psychologically safe inclusive educational environment provides the child with an event community, stimulates his active interaction and cooperation with other people. An important condition for the implementation of this component is the formation of psychological readiness for positive interaction among all subjects of an inclusive educational environment and the absence of discrimination.

Assessment of the psychological safety of an inclusive educational environment was carried out using the method of expert assessments. The experts were primary education teachers (129 teachers with different lengths of pedagogical activity) and two groups of parents included in inclusive educational practice: parents raising children of primary school age with disabilities (81 people) and 
parents raising children with normotypic development (273 people). The total sample size was 483 respondents.

This selection is due to several factors:

1) Teachers are the leading subjects of inclusive education, since it is with the inclusive educational environment that the teacher has a specific situation that requires special efforts from the teacher to build a positive, "non-violent" interaction based on subject-subject relations with the child with limited health capabilities [2];

2) In turn, parents, parental satisfaction is a powerful factor that affects the effectiveness of inclusive education and the psychological climate of participants in educational relations. In an inclusive educational environment, parents of different categories of students combine and interact on the basis of respect for each other, understanding and acceptance of differences, their willingness to jointly teach children [9]. The attitude of parents to the educational environment, their degree of satisfaction from the standpoint of the conditions and development opportunities of their child is an important factor affecting the implementation of inclusive practices in the educational organization.

Psychological safety criteria were studied using the following research methods:

1) The attitude towards an inclusive educational environment (positive, neutral, negative) was studied using the survey method and the method of expert assessments: questionnaire for the teaching staff of the school, aimed at studying the attitude of teachers to inclusive education of children with disabilities;

2) Satisfaction with the main substantive components of an inclusive educational environment (subject-semantic, substantive-methodical, communication-organizational) was studied using the methodology for assessing the readiness of an educational institution for inclusive education (a map for a teacher) [6]; a questionnaire for parents [8], aimed at studying parents' satisfaction with the conditions of joint education; author's methodology "Diagnostics of the readiness of teachers for the implementation of inclusive education" (E.S. Slusareva);

3) For the study of such a criterion as "protection from psychological violence" the above methods were used to examine such aspects as: the psychological climate in an educational institution, the identification of discrimination in an inclusive educational environment; risks arising in the process of interaction of subjects of an inclusive educational environment. In addition, a special diagnostic toolkit was used - a questionnaire for studying the features of the inclusive educational environment of an educational institution for teachers. The questionnaire is based on the questions developed by I.A. Baeva based on the theory of psychological safety of the educational environment "Questionnaire for studying the characteristics of the educational environment of an educational institution for teachers" [1]. The questions of the questionnaire are aimed at studying the ideas of teachers about the phenomenon of psychological safety of an inclusive educational environment, a sense of personal security in an inclusive educational environment.

\subsection{Empirical results}

Let us turn to a quantitative-qualitative analysis of the results of an empirical study.

In the study of the criterion "attitude to an inclusive educational environment" we obtained the following results.

If we are talking about an inclusive educational environment, in which 1-2 children with disabilities are included, then teachers consider this training quite effective. The teachers' answers were distributed as follows: the most positive attitude towards the inclusion of children with visual impairment (55\%), children with poor health (47\%), children with speech impairments (41\%), and children with impaired musculoskeletal functions $(38 \%)$.

Teachers are extremely negative about the co-education of children with affective disorders $(38 \%)$ and mental retardation $(41 \%)$. A number of educators $(8 \%)$ note the experience of such 
negative emotional states as hostility, a feeling of antipathy, and, sometimes, an aversion to a child who has severe disorders (especially in cases of severe and multiple developmental disorders), which clearly affects the psychological safety of all subjects of educational relations in an inclusive educational environment.

With the increase in the number of children in the classroom to 4-5 people, regardless of the child's health and interaction limitations, teachers question the effectiveness of joint learning.

This point of view is shared by parents of children with different psychophysiological status. Summarizing the obtained quantitative data, we can note that parents raising children with normal psychophysical development believe that the conditions of special (correctional) educational institutions are most suitable for children with all types of deviant development. While parents raising children with disabilities believe that if we are talking about children with severe disorders that limit their adaptation in the educational environment (children with affective and mental disorders), then the most optimal conditions are special (correctional) schools ( $86 \%$ of respondents). Whereas if we are talking about children with developmental deficits (sensory, motor, speech), parents consider the conditions of secondary schools $(45 \%)$ and the conditions of special (correctional) schools to be equally attractive (41\%).

Thus, the first factor that affects the positive attitude and psychological well-being of teachers and parents as subjects of an inclusive educational environment is the number of children included and the nature of the child's limited abilities (mental, sensory, motor, affective, etc.).

Considering the criterion "satisfaction with the main substantive components of an inclusive educational environment" (subject-semantic, substantive-methodical, communicationorganizational), we ranked the data as follows.

The greatest satisfaction of both teachers and parents (95\%) was noted in terms of the subjectsemantic component of an inclusive educational environment: in particular, satisfaction was noted with the material and technical conditions of educational organizations, the degree of accessibility of the institution for all categories of children with disabilities, the presence of appropriate classrooms, and the use of special equipment, didactic materials, etc.

The next preference is the communication and organizational component of an inclusive educational environment (satisfaction rate $-88 \%$ ), which is expressed in such indicators as: a positive psychological climate in the educational institution, goodwill in the relationship between teacher and students, the presence of mutual assistance and mutual support in student relations, partnerships between teachers and parents, etc.

Both groups of respondents expressed the least satisfaction with regard to the contentmethodological component of an inclusive educational environment: satisfaction with this component is $56 \%$.

The least quantitative data on the part of parents $(48 \%)$ were obtained for such indicators as: the content of the main educational program, the compliance of the educational program with the educational needs and capabilities of the child, the presence and content of the correctional work program, and the adequacy of the correction methods and technologies used.

Teachers $(72 \%)$ also noted a lack of satisfaction with the content-methodical component of an inclusive educational environment, which is reflected in the significant severity of psychological barriers that arise in the process of interaction between a teacher and a student with disabilities:

- theoretical (barriers related to the lack of knowledge and skills related to building the child's educational route in the form of an adapted basic general educational program, an adapted educational program, an individual child development program, etc.);

- conative or barriers of action associated with the difficulty of transferring knowledge to the practice of co-education of children with disabilities. 
Considering such an indicator as the participation of parents in an inclusive educational process (joint discussion with experts on optimal psychological and pedagogical technologies, the participation of parents in discussing the child's individual route, etc.), parents rated it as an "insufficiently frequent invitation to participate" (68\%). In turn, teachers also note the insufficient involvement of parents in the formation of an educational request and building an individual educational trend for their child, who has limited health capabilities and the special educational needs arising from them.

Most of the respondents noted the need for a focused system for the formation of professional (among teachers) and psychological readiness (among teachers and parents) for positive interaction in an inclusive educational environment $-82 \%$.

Thus, the second factor affecting the psychological security of an inclusive educational environment is the unpreparedness (professional, psychological) of its participants for building a positive interaction.

And the final criterion was the "protection from psychological violence" of the subjects of an inclusive educational environment.

As soon as children with disabilities are included in the educational environment, we are faced with a number of risks and psychological threats:

1. Psychological violence, which in the educational environment can manifest itself in the form of verbal aggression against a child with disabilities: insults, ridicule, etc.

2. Non-recognition by the child with disabilities of the reference importance of the educational environment of the educational institution, as a result of which the child refuses to attend school. Often this problem is "solved" by transferring the child to an individual form of education, but in this way we discredit the very idea of inclusive education, based on respect for the rights and dignities of all children without exception.

3. The lack of satisfaction in personal-confidential communication and the main characteristics of the interaction process of all participants in the educational environment and, as a result, the emotional discomfort of all subjects of the educational space.

4. Underdeveloped psychological assistance systems in educational institutions. Lack of timely assistance and support both at the adaptation stage and at the subsequent stages of joint training can lead to a violation of the mental and psychological health of all subjects of the inclusive educational process.

The study shows that parents and teachers consider as risks of a comprehensive school: psychological problems of adopting "special" children in secondary schools $(70 \%)$; lack of preparedness of the children's team in moral and psychological terms (64\%).

Hence, the third factor affecting the psychological safety of an inclusive educational environment is the emotional relationship of the child with disabilities with adults and the child with other children.

\section{Summary}

Summarizing the theoretical views of scientists and the results of empirical research, it can be noted that overcoming the above risks is possible only if a psychologically safe inclusive educational environment is built, the main content of which is to build a positive interaction of all subjects of educational relations and protect (ensure security) the identity of all participants in the educational environment through creation of conditions for the most complete development and realization of their individual potentials. 


\section{References}

[1] I.A. Baeva, Psychological safety in education. SPb .: Publishing house "SOYUZ", 2002: 271.

[2] I.V. Vachkov, A multi-subject approach to the interaction of subjects of an inclusive educational environment // Psychological and pedagogical foundations of inclusive education: a collective monograph / Otv. ed. S.V. Alekhine. M .: MGPPU, Buki Vedi LLC, 2013: 84-96.

[3] L.S. Vygotsky, Pedagogical psychology / Under the editorship of V. V. Davydov. Moscow: Pedagogika, 1991. 480.

[4] A.A. Koroleva, Assessment of the psychological safety of the educational environment of a boarding school by adolescents with a delay in mental development // Personality, family and society: issues of pedagogy and psychology: Sat. Art. by mater. IX international scientific-practical conf. Part III. Novosibirsk: SibAK, 2011: 128.

[5] Yu.D. Gakame, Organization of a psychologically safe educational environment in the context of inclusive education // Concept. 2015, (37): 251-255.

[6] O.S. Kuzmina, Preparing teachers for work in an inclusive education: diss ... candidate of pedagogical sciences. Omsk, 2015: 319.

[7] E.B. Laktionova, Psychological examination of the educational environment: author. Thesis ... Dr. psychol.: 19.00.07. St. Petersburg, 2013: 49.

[8] Psychological and pedagogical assessment of an inclusive educational environment / S.A. Kalashnikova, E.V. Zvoleyko. Chita: ZabSU, 2015: 263.

[9] I.N. Simaeva, Problems of readiness for inclusive education of parents of students // Bulletin of the Baltic Federal University named after I. Kant. 2015 (11): 54-62.

[10] Creation and testing of a model of psychological and pedagogical support of inclusive practice: a Toolkit / Ed. S.V. Alekhina, M.M. Semago. M .: MGPPU, 2012: 156.

[11] A.N. Sukhov, Social psychology of security. M.: ACADEMY, 2002: 256.

[12] S.V. Tarasov, Educational environment: concept, structure, typology // Bulletin of the Leningrad State University. A.S. Pushkin. 2011: 133-138.

[13] A.V. Tyurin, Inclusive educational environment as an acmeological adaptation tool // Bulletin of the Moscow State Humanitarian and Economic Institute. 2013.4 (16): 52-63.

[14] L.G.Yurchenko, N.I. Kovaleva, Ensuring the psychological safety of participants in an inclusive educational process. Historical and socio-educational thought. 2016. Volume 8.5. (3): 189-194. 